\title{
Textile CAD Analysis for Warp and Weft Patterning
}

\author{
Shariful Islam ${ }^{1 *}$, Amirul Islam ${ }^{1}$, Suza Ahmed ${ }^{1}$, Mohammad Arif Billah $^{2}$ and Rabeya Islam ${ }^{3}$ \\ ${ }^{1}$ Bangladesh University of Textiles, Bangladesh \\ ${ }^{2}$ University of Chittagong, Bangladesh \\ ${ }^{3}$ City University, Bangladesh
}

*Corresponding author: Shariful Islam, Bangladesh University of Textiles, Dhaka, Bangladesh

Submission: 眥 January 24, 2018; Published: 㘹 February 19, 2018

\begin{abstract}
The aim of this paper is to do patterning in both warp and weft direction against computer aided design for a woven fabric. Patter design is given by the buyer to the fabric manufacturer to make a yarn dyed fabric where the original design or color patter will be reflected in the fabric that will be made. How many yarns will be needed in warp direction and how many yarns will be needed in weft direction that is also shown in this project. This project work is not only a paper work but also a practical solution for the textile learners, designers, fabric developer and also to many textile experts. Textile design CAD contains, the pattern design of the fabric, that is given by the buyer, to the fabric manufacturer, to produce a fabric, where in fabric, will have the actual and exact appearance and look, as like as the CAD. Textile patterning CAD analysis is a step by step examine on original CAD. Actually, textile CAD analysis is the methodical calculating-inspection on CAD, for setting up the pattern design of paper into a fabric, through longitudinal and transverse direction of fabrics. The courses of actions those are applied by the engineers during CAD analysis has been stated in this paper.
\end{abstract}

Keywords: CAD; Application of CAD; CAD Analysis; Warp patterning; Weft patterning

\section{Introduction}

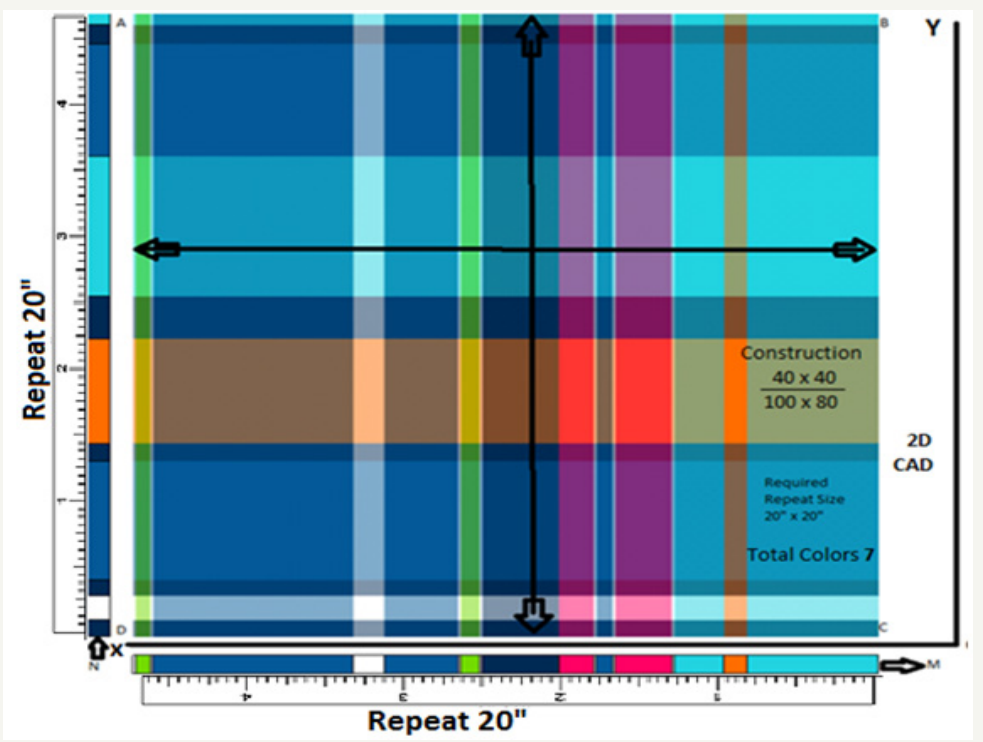

Figure 1: Textile CAD.

There is a vast importance of this paper for calculating the number of yarns to be required in a full repeat of the CAD. This paper will help to get information about the buyer's CAD and its repeat size, to get an overall idea about the pattern design, to scrutinize the pattern design and duration of CAD, to calculate the number of yarns to be required in a stripe color or in a full repeat, to make a new yarn dyed fabric as per CAD design. Basically, the design which is created by means of a software in computer for further use, where repeat units are shown, which expresses the real image of the larger things in a miniature form, which helps to build something after following the design, that design is called CAD design/CAD [1]. CAD is the application of computer to create, modify, analyze, or optimize a design. Generally, people apply CAD software for raising the productivity of the designer, improve or 
develop the excellence of the design, establish communications with records, and to build a record/database for manufacturing. Output of CAD is habitually in the form of electronic files as like print, machining or different manufacturing schemes.

\section{Textile CAD analysis (warp and weft patterning)}

For making warp and weft pattern, customers are giving some design that is called CAD. The fabric will be as same as like CAD after making the fabric. CAD will show the repeat size of the fabric. Sometimes customers are giving the CADs which are smaller than the fabric repeat size [2].

Suppose, the whole CAD describes only a repeat of 20 inches in the fabric. That means, after making the fabric, the repeat will be 20 inches in fabric. But the CAD itself is not equal to 20 inches in length or width. That time we need to convert the width and length of the CAD for making a perfect warp and weft pattern. By using the CAD, designers will be able to make a perfect warp and weft pattern, color sequence, repeat dwell in the cloth etc (Figure $1 \& 2$ ).

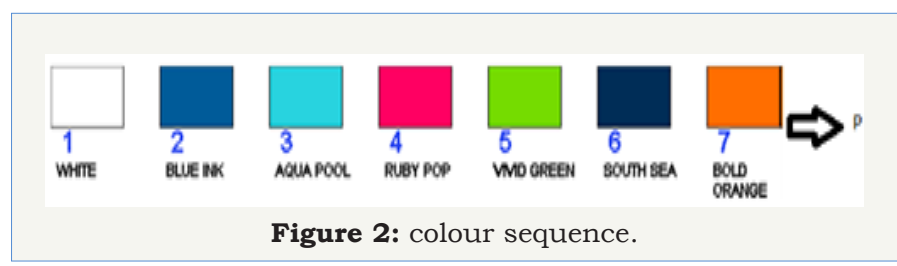

\section{CAD description:}

- This is a 2D CAD or Two Dimensional CAD.

- This CAD is used for making warp and weft pattern in fabric.

- This CAD also shows the color sequences.

- The horizontal arrow mark shows warp pattern in CAD which is in $\mathrm{X}$ axis or OX axis.

- The vertical arrow mark shows weft pattern in CAD which is in Y-axis or OY axis.

- The arrow marks show the repeat unit in the CAD both in warp and weft direction.

- There is only one repeat is available in this CAD.

- $\mathrm{ABCD}$ expresses the main area of the CAD

- $\mathrm{ABCD}$ is the full and only one repeat.

- OX and OY are the two axes of the CAD, whose are two dimensions.

- "M" expresses the warp color sequences.

- "N" expresses the weft color sequences.

- "P" expresses the color names.

- During warp patterning, we have to go XO direction that means from left to right.

- During weft patterning, we have to go OY direction that means from down to up.
- The required repeat size is 20 " $\times 20$ ", which is written inside the CAD.

- The required repeat size is a square repeat as required warp and required weft repeat size are the same as like as a square, but this CAD is not square.

- Here in this $\mathrm{CAD}, \mathrm{AB}$ or $\mathrm{DC} \neq \mathrm{AD}$ or $\mathrm{BC}$. That refers, it is not a square $\mathrm{CAD}$.

- 20 " $\times 20$ " that is 20 " repeat in warp direction and 20 " repeat in weft direction.

- 20" in warp direction means if we go to XO direction in fabric, that time $\mathrm{DC}$ or $\mathrm{AB}$ will be 20 " in fabric surface.

- 20 " in weft direction means if we go to OY direction in fabric, that time CB or DA will be 20 " in fabric surface.

- The original CAD size we can get by measuring with a linear scale in inch scale as repeat size is mentioned in inch scale.

- In normal A4 size paper this CAD is 5.027" inch in warp direction and 4.7520" inch in weft direction.

- So in $\mathrm{CAD}, \mathrm{AB}$ or $\mathrm{DC}=5.027 "$

- $\quad$ And in $\mathrm{CAD}, \mathrm{AD}$ or $\mathrm{BC}=4.7520 "$

- Construction of the fabric is $40 \times 40 / 100 x 80$ that is very important for CAD Calculation.

- There are 7 colors in the CAD which is written and color sequence mentioned the color names ("P").

- During the time of CAD calculation, we have to convert the original measurement in scale with required repeat size.

\section{CAD analysis:}

\section{A. $1^{\text {st }}$ step of CAD analysis}

This is the step of making a balance between CAD and fabric by means of a fraction.

There is a variation in CAD repeat size and required repeat size in fabric. Repeat size in fabric and in CAD may not be same. Most often, CAD repeat size is smaller and required repeat size in fabric is larger. That time it is necessary to convert the repeat size from CAD to fabric by using a fraction [3]. During the time of patterning warp and weft way, this fraction will be helpful for knowing the number of yarn to be used in both warp and weft direction.

Suppose the required repeat size in fabric is 20 inches both in warp and weft way. In normal A4 size paper, the CAD design cannot becomes 20 inches. Guess, the repeat size becomes 5.027" inches in CAD (from left to right, DC) in normal A4 size paper (In warp way) by measuring with linear scale. So fabric repeat size is 20 " where CAD repeat size is 5.027 " (DC).

Moreover, in weft way, from down to up in CAD (DA), the repeat size becomes 4.75" (DA) in the normal A4 size paper [4]. That time there remains a variation in repeat size. In this circumstance, we 
need to convert the repeat size from CAD to required repeat size in fabric as like below:

The fraction in warp way, (from left to right in CAD, DC) (OX axis)

5.027 " inches (by linear scale) in CAD is equal to $=20$ inches in fabric.

1 inch in CAD is equal to $=20 / 5.027$ inches in fabric.

$=3.9785$ (This is the warp fraction or warp variation)

The fraction in weft way, (from down to up in CAD, DA) (OY axis)

$4.75^{\prime \prime}$ inches (by linear scale, DA) in CAD is equal to $=20$ inches in fabric.

1 inch in CAD is equal to $=20 " / 4.75^{\prime \prime}$ inches in fabric.

$=4.21$ (This is the weft fraction or weft variation)

These fractions (both warp and weft) will be used in every time for making pattern both in warp and weft way for this CAD. Here warp and weft required repeat size in fabric is same, as it is a square CAD. These fractions will make-up the variation of CAD repeat size and original required repeat size in fabric.

\section{B. $2^{\text {nd }}$ step of CAD analysis}

This is the step of knowing color sequences and Color Measurement of warp and weft way. After knowing the area of yarn in each color of a pattern, we have to find out the total number of required yarn in a repeat. Then we have to arrange the warp and weft pattern systematically. Warp color sequence is "M" and weft color sequence is "N".

Table 1: Warp color sequence and color measurement.

\begin{tabular}{|c|c|c|}
\hline S.N & Color Name & Area (Measurement) \\
\hline 01 & vivid green & $3.5 \mathrm{~mm}$ or 0.1377 inches \\
\hline 02 & blue ink & $3.35 \mathrm{~cm}$ or 1.3188 inches \\
\hline 03 & white & $6 \mathrm{~mm}$ or 0.2362 inches \\
\hline 04 & blue ink & $1.27 \mathrm{~cm}$ or 0.5000 inches \\
\hline 05 & vivid green & $5 \mathrm{~mm}$ or 0.19685 inches \\
\hline 06 & south sea & $1.4 \mathrm{~cm}$ or 0.55118 inches \\
\hline 07 & ruby pop & $6 \mathrm{~mm}$ or 0.23622 inches \\
\hline 08 & blue ink & $4 \mathrm{~mm}$ or 0.15748 inches \\
\hline 09 & ruby pop & $1 \mathrm{~cm}$ or 0.3937 inches \\
\hline 10 & aqua pool & $8 \mathrm{~mm}$ or 0.31496 inches \\
\hline 11 & bold orange & $4 \mathrm{~mm}$ or 0.15748 inches \\
\hline 12 & aqua pool & $2.1 \mathrm{~cm}$ or 0.82677 inches \\
\hline & Total Color sequence $=12$ & Total area $=5.027342$ inches \\
\hline
\end{tabular}

Warp color sequence and color measurement ("M" -in CAD):

Color sequence of CAD will create both the warp and weft pattern. If I consider the warp pattern, (from left to right in CAD, DC) the first color is vivid green. Then the color sequence is blue ink, white, blue ink, vivid green, south sea, ruby pop, blue ink, ruby pop, aqua pool, bold orange and the last color is aqua pool (Table 1).
If I consider the weft pattern, (from down to up in CAD, DA) the first color is south sea. Then the color sequence is white, south sea, blue ink, south sea, bold orange, south sea, aqua pool, blue ink, south sea. And the last color is aqua pool (Table 2).

Table 2: Weft color sequence and color measurement.

\begin{tabular}{|c|c|c|}
\hline S.N & Color Name & Area (Measurement) \\
\hline 01 & South sea & $3.5 \mathrm{~mm}$ or $0.137795^{\prime \prime}$ inches \\
\hline 02 & White & $4.5 \mathrm{~mm}$ or $0.17716^{\prime \prime}$ inches \\
\hline 03 & South sea & $3.5 \mathrm{~mm}$ or $0.137795^{\prime \prime}$ inches \\
\hline 04 & Blue ink & $2.1 \mathrm{~cm}$ or $0.826771^{\prime \prime}$ inches \\
\hline 05 & South sea & $3.5 \mathrm{~mm}$ or $0.137795^{\prime \prime}$ inches \\
\hline 06 & Bold orange & $2.2 \mathrm{~cm}$ or $0.866141^{\prime \prime}$ inches \\
\hline 07 & South sea & $8.5 \mathrm{~mm}$ or $0.3347^{\prime \prime}$ inches \\
\hline 08 & Aqua pool & $2.65 \mathrm{~cm}$ or $1.0433^{\prime \prime}$ inches \\
\hline 09 & Blue ink & $2.1 \mathrm{~cm}$ or $0.826771^{\prime \prime}$ inches \\
\hline 10 & South sea & $4.5 \mathrm{~mm}$ or $0.177165^{\prime \prime}$ inches \\
\hline 11 & Aqua pool & $2.2 \mathrm{~mm}$ or $0.0866141^{\prime \prime}$ inches \\
\hline & Total Color sequence $=12$ & Total area $=4.7520^{\prime \prime}$ inches \\
\hline
\end{tabular}

Weft color sequence and color measurement ("N" -in CAD):

\section{C. $3^{\text {rd }}$ step of CAD analysis}

This is the step of identifying the actual number of yarn available in each color. Every color way will be, measured here by dint of a liner scale. Converting the measurement into number of yarn is the main task of this step.

Some area in CAD design may be very tinny in paper. Sometimes the sequences of color may be less than 1 centimeter. So we need to measure the color way in millimeter scale. After measuring the color sequence in millimeter scale (by linear scale), we will convert this in centimeter scale (by dividing 10 , as $1 \mathrm{~cm}=10 \mathrm{~mm}$ ). Then convert this thing to inch scale (by dividing 2.54 , as $1 \mathrm{inch}=2.54 \mathrm{~cm}$ ). Now multiply this value with EPI (in case of warp patterning) or PPI (in case of weft patterning). Again multiply this value with the fraction. Finally we will get the number of yarn in pattern [5]. By doing this practice again and again (until the repeat finishes) we will be able to find each and every yarn in the full repeat.

\section{Warp yarn identifying}

Suppose, for a given construction $(40 \times 40 / 100 \times 80)$ we will consider the first pattern color. Here in this CAD, from left to right, DC, vivid green is the first color and that is $3.5 \mathrm{~mm}$. In cm scale, it is $0.35 \mathrm{~cm}$ (dividing by 10). In inch scale, it will be 0.13779 inch (dividing by 2.54). Now multiply this value (0.13779) with fraction (3.9785) and EPI (100). So this value will be 54.783945 or 55 yarn. By doing this practice again and again (until the repeat finishes) we will get the total number of yarn will be required in a repeat [6].

The sequence will be like this

Millimeter $\rightarrow$ Centimeter $\rightarrow$ Inches $\rightarrow$ (Inches $\mathrm{x}$ Fraction $\mathrm{x}$ EPI) $=$ Total number of Yarn. 


\section{Vivid Green}

$=3.5 \mathrm{~mm}$

$=3.5 \mathrm{~mm} / 10$

$=0.35 \mathrm{~cm}$

$=0.35 \mathrm{~cm} / 2.54$

$=0.1377$ inch

$=0.1377$ inch $\mathrm{x}$ fraction (3.9785) $\mathrm{x}$ EPI (100)

$=54.783945$

$=55$ yarn.

\section{Blue Ink}

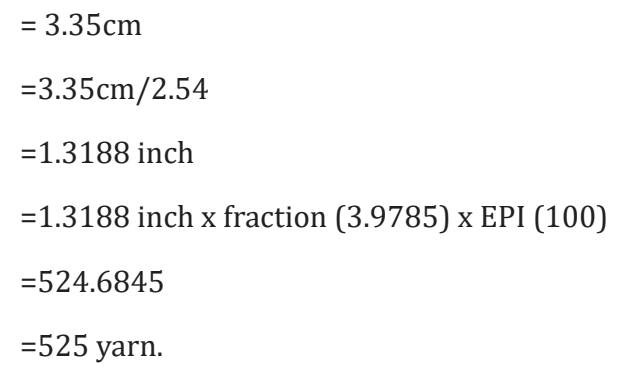

\section{White}

$=6 \mathrm{~mm}$
$=6 \mathrm{~mm} / 10$
$=0.6 \mathrm{~cm}$
$=0.6 \mathrm{~cm} / 2.54$
$=0.2362$ inch
$=0.2362$ inch x fraction $(3.9785) \times$ EPI $(100)$
$=93.9721$
$=94$ yarn

\section{Blue Ink}

$$
\begin{aligned}
& =1.27 \mathrm{~cm} \\
& =1.27 \mathrm{~cm} / 2.54 \\
& =0.5000 \text { inch } \\
& =0.5000 \text { inch } \times \text { fraction }(3.9785) \times \text { EPI }(100) \\
& =198.925 \\
& =199 \text { yarns }
\end{aligned}
$$

\section{Vivid Green}

$$
\begin{aligned}
& =5 \mathrm{~mm} \\
& =5 \mathrm{~mm} / 10 \\
& =0.5 \mathrm{~cm} \\
& =0.5 \mathrm{~cm} / 2.54
\end{aligned}
$$

$=0.19685$ inch

$=0.19685$ inch $\mathrm{x}$ fraction (3.9785) x EPI (100)

$=78.31$

$=78$ yarn

\section{South Asia}

$=1.4 \mathrm{~cm}$

$=1.4 \mathrm{~cm} / 2.54$

$=0.55118$ inch

$=0.55118$ inch $\mathrm{x}$ fraction $(3.9785) \mathrm{x}$ EPI (100)

$=219.2869$

$=219$ yarn.

\section{Ruby Pop}

$=6 \mathrm{~mm}$

$=6 \mathrm{~mm} / 10$

$=0.6 \mathrm{~cm}$

$=0.6 \mathrm{~cm} / 2.54$

$=0.23622 \mathrm{inch}$

$=0.23622$ inch $\mathrm{x}$ fraction (3.9785) x EPI (100)

$=93.98$

=94 yarn.

\section{Blue Ink}

$=4 \mathrm{~mm}$

$=4 \mathrm{~mm} / 10$

$=0.4 \mathrm{~cm}$

$=0.4 \mathrm{~cm} / 2.54$

$=0.15748 \mathrm{inch}$

$=0.15748$ inch $\mathrm{x}$ fraction (3.9785) x EPI (100)

$=62.6534$

$=63$ yarn.

\section{Ruby Pop}

$$
\begin{aligned}
& =1 \mathrm{~cm} \\
& =1 \mathrm{~cm} / 2.54 \\
& =0.3937 \mathrm{inch} \\
& =0.3937 \text { inch } \times \text { fraction }(3.9785) \times \text { EPI }(100) \\
& =156.6338 \\
& =157 \text { yarn }
\end{aligned}
$$

Aqua Pool 
$=8 \mathrm{~mm}$

$=8 \mathrm{~mm} / 10$

$=0.8 \mathrm{~cm}$

$=0.8 \mathrm{~cm} / 2.54$

$=0.31496$ inch

$=0.31496$ inch $\mathrm{x}$ fraction $(3.9785) \times$ EPI (100)

$=125.3068$

$=125$ yarn

\section{Bold Orange}

$=4 \mathrm{~mm}$
$=4 \mathrm{~mm} / 10$
$=0.4 \mathrm{~cm}$
$=0.4 \mathrm{~cm} / 2.54$
$=0.15748$ inch
$=0.15748$ inch $x$ fraction $(3.9785) \times$ EPI $(100)$
$=62.6534$
$=63$ yarn

\section{Aqua Pool}

$=2.1 \mathrm{~cm}$

$=2.1 \mathrm{~cm} / 2.54$

$=0.82677$ inch

$=0.82677$ inch $\mathrm{x}$ fraction $(3.9785) \times$ EPI (100)

$=328.9311$

=329 yarn (Table 3 ).

Table 3: Warp color sequence.

\begin{tabular}{|c|c|c|c|}
\hline S.N & Color Name & Area (Measurement) & yarns \\
\hline 01 & vivid green & 0.13 inches & 55 \\
\hline 02 & blue ink & 1.31 inches & 525 \\
\hline 03 & white & 0.23 inches & 94 \\
\hline 04 & blue ink & 0.5 inches & 199 \\
\hline 05 & vivid green & 0.19 inches & 78 \\
\hline 06 & south sea & 0.55 inches & 219 \\
\hline 07 & ruby pop & 0.23 inches & 94 \\
\hline 08 & blue ink & 0.15 inches & 63 \\
\hline 09 & ruby pop & 0.39 inches & 157 \\
\hline 10 & aqua pool & 0.31 inches & 125 \\
\hline 11 & bold orange & 0.15 inches & 63 \\
\hline 12 & aqua pool & 0.82 inches & 329 \\
\hline & Total colors 12 & Total area 4.95 inches & $2001=$ Total yarns \\
\hline
\end{tabular}

Warp color sequence, color measurement \& yarns:

\section{Weft yarn identifying}

In this $\mathrm{CAD}$, the given construction is $40 \mathrm{x} 40 / 100 \mathrm{x} 80$ that we will use for identifying the weft pattern. Here in this CAD, from down to up (DA), south sea is the first color and that is $3.5 \mathrm{~mm}$. In cm scale, it is $0.35 \mathrm{~cm}$ (dividing by 10 ). In inch scale, it will be 0.13779 " inch (dividing by 2.54). Now multiply this value ( 0.13779 ") with fraction (4.21) and PPI (80). So this value will be 46.4094 or 46 yarns [7]. By doing this practice again and again (until the repeat finishes) we will get the total number of yarn will be required in a repeat.

The sequence will be like this

Millimeter $\rightarrow$ Centimeter $\rightarrow$ Inches $\rightarrow$ (Inches x Fraction $\mathrm{x}$ PPI) $=$ Total number of Yarn.

\section{South sea}

$$
\begin{aligned}
& =3.5 \mathrm{~mm} \\
& =3.5 \mathrm{~mm} / 10 \\
& =0.35 \mathrm{~cm} \\
& =0.35 \mathrm{~cm} / 2.54 \\
& =0.1377^{\prime \prime} \text { inch } \\
& =0.1377^{\prime \prime} \text { inch } \times \text { fraction }(4.21) \times \text { PPI }(80) \\
& =46.409448 \\
& =46 \text { yarns. }
\end{aligned}
$$

\section{White}

$$
\begin{aligned}
& =4.5 \mathrm{~mm} \\
& =4.5 \mathrm{~mm} / 10 \\
& =0.45 \mathrm{~cm} \\
& =0.45 \mathrm{~cm} / 2.54 \\
& =0.17716^{\prime \prime} \text { inch } \\
& =0.17716^{\prime \prime} \text { inch x fraction }(4.21) \times \text { PPI }(80) \\
& =59.6692 \\
& =60 \text { yarns. }
\end{aligned}
$$

\section{South sea}

$=3.5 \mathrm{~mm}$

$=3.5 \mathrm{~mm} / 10$

$=0.35 \mathrm{~cm}$

$=0.35 \mathrm{~cm} / 2.54$

$=0.1377^{\prime \prime}$ inch

$=0.1377 "$ inch $\mathrm{x}$ fraction $(4.21) \mathrm{x}$ PPI (80)

$=46.409448$

$=46$ yarns. 


\section{Blue ink}

$$
\begin{aligned}
& =2.1 \mathrm{~cm} \\
& =2.1 \mathrm{~cm} / 2.54 \\
& =0.826771^{\prime \prime} \text { inch } \\
& =0.826771^{\prime \prime} \text { inch } \times \text { fraction }(4.21) \times \text { PPI }(80) \\
& =278.4564 \\
& =278 \text { yarns. }
\end{aligned}
$$

\section{South sea}

$=3.5 \mathrm{~mm}$

$=3.5 \mathrm{~mm} / 10$

$=0.35 \mathrm{~cm}$

$=0.35 \mathrm{~cm} / 2.54$

$=0.1377^{\prime \prime}$ inch

$=0.1377 "$ inch $\mathrm{x}$ fraction $(4.21) \mathrm{x}$ PPI (80)

$=46.409448$

$=46$ yarns.

\section{Bold orange}

$$
\begin{aligned}
& =2.2 \mathrm{~cm} \\
& =2.2 \mathrm{~cm} / 2.54 \\
& =0.866141^{\prime \prime} \text { inch } \\
& =0.866141^{\prime \prime} \text { inch } \times \text { fraction }(4.21) \times \text { PPI }(80) \\
& =291.7162 \\
& =292 \text { yarns. }
\end{aligned}
$$

\section{South sea}

$=8.5 \mathrm{~mm}$

$=8.5 \mathrm{~mm} / 10$

$=0.85 \mathrm{~cm}$

$=0.85 \mathrm{~cm} / 2.54$

$=0.3347^{\prime \prime}$ inch

$=0.3347 "$ inch $\mathrm{x}$ fraction $(4.21) \mathrm{x}$ PPI (80)

$=112.7269$

=113 yarns.

\section{Aqua pool}

$=2.65 \mathrm{~cm}$

$=2.65 \mathrm{~cm} / 2.54$

$=1.0433^{\prime \prime}$ inch

$=1.0433 "$ inch $\mathrm{x}$ fraction (4.21) x PPI (80)
$=351.38$

$=352$ yarns

Blue ink

$=2.1 \mathrm{~cm}$

$=2.1 \mathrm{~cm} / 2.54$

$=0.826771^{\prime \prime}$ inch

$=0.826771 "$ inch $\mathrm{x}$ fraction $(4.21) \times$ PPI $(80)$

$=278.4564$

$=278$ yarns.

\section{South sea}

$=4.5 \mathrm{~mm}$

$=4.5 \mathrm{~mm} / 10$

$=0.45 \mathrm{~cm}$

$=0.45 \mathrm{~cm} / 2.54$

$=0.177165^{\prime \prime}$ inch

$=0.177165 "$ inch $\mathrm{x}$ fraction (4.21) x PPI (80)

$=59.6691$

$=60$ yarns.

\section{Aqua pool}

$=2.2 \mathrm{~mm}$

$=2.2 \mathrm{~mm} / 10$

$=0.22 \mathrm{~cm}$

$=0.22 \mathrm{~cm} / 2.54$

$=0.0866141$ " inch

$=0.0866141 "$ inch $\mathrm{x}$ fraction (4.21) x PPI (80)

$=29.1716$

$=29$ yarns $($ Table 4$)$.

Table 4: Weft color sequence.

\begin{tabular}{|c|c|c|c|}
\hline S.N & Color Name & Area (Measurement) & yarns \\
\hline 01 & South sea & $3.5 \mathrm{~mm}$ or $0.137795^{\prime \prime}$ inches & 46 \\
\hline 02 & White & $4.5 \mathrm{~mm}$ or $0.17716^{\prime \prime}$ inches & 60 \\
\hline 03 & South sea & $3.5 \mathrm{~mm}$ or $0.137795^{\prime \prime}$ inches & 46 \\
\hline 04 & Blue ink & $2.1 \mathrm{~cm}$ or $0.826771^{\prime \prime}$ inches & 278 \\
\hline 05 & South sea & $3.5 \mathrm{~mm}$ or $0.137795^{\prime \prime}$ inches & 46 \\
\hline 06 & Bold orange & $2.2 \mathrm{~cm}$ or $0.866141^{\prime \prime}$ inches & 292 \\
\hline 07 & South sea & $8.5 \mathrm{~mm}$ or $0.3347^{\prime \prime}$ inches & 113 \\
\hline 08 & Aqua pool & $2.65 \mathrm{~cm}$ or $1.0433^{\prime \prime}$ inches & 351 \\
\hline 09 & Blue ink & $2.1 \mathrm{~cm}$ or $0.826771^{\prime \prime}$ inches & 278 \\
\hline 10 & South sea & $4.5 \mathrm{~mm}$ or $0.177165^{\prime \prime}$ inches & 60 \\
\hline
\end{tabular}




\begin{tabular}{|c|c|c|c|}
\hline 11 & Aqua pool & $2.2 \mathrm{~mm}$ or $0.0866141^{\prime \prime}$ inches & 29 \\
\hline & $\begin{array}{c}\text { Total color } \\
\text { sequences 11 }\end{array}$ & Total area $=4.7520^{\prime \prime}$ inches & $\begin{array}{c}1599=\text { Total } \\
\text { yarns }\end{array}$ \\
\hline
\end{tabular}

Weft color sequence, color measurement \& yarns

\section{4th step of CAD analysis}

This is the step of making color sequence chart, which will be used during indirect or sectional warping in warping machine. In this chart, every information will be available about a repeat in the CAD as like number of each colored yarn, total number of yarn in a repeat [8], how much time a color comes in a repeat. Total number of yarn is equal to the total number of cones in a repeat. From here we can know the yarn quantity in a repeat.

\section{Warp pattern chart}

(Table 5)

Table 5: warp pattern chart.

\begin{tabular}{|c|c|c|c|c|c|c|c|c|c|c|}
\hline $\mathbf{1}^{\text {st }}$ & $\mathbf{2}^{\text {nd }}$ & $\mathbf{3}^{\text {rd }}$ & $\mathbf{4}^{\text {th }}$ & $\mathbf{5}^{\text {th }}$ & $\mathbf{6}^{\text {th }}$ & $\mathbf{7}^{\text {th }}$ & $\mathbf{8}^{\text {th }}$ & $\mathbf{9}^{\text {th }}$ & $\mathbf{1 0}^{\text {th }}$ & $\mathbf{1 1}^{\text {th }}$ \\
\hline S.N & Color Names & & & & & & & & Frequency & Total Yarns Or Total Cones \\
\hline 01 & White & & & 94 & & & & & 1 Time & $=94$ yarns \\
\hline 02 & Blue Ink & & 525 & 199 & & 63 & & & 3 Times & $=787$ yarns \\
\hline 03 & Aqua Pool & & & & & & 125 & 329 & 2 Times & $=454$ yarns \\
\hline 04 & Ruby Pop & & & & 94 & 157 & & & 2 Times & $=133$ yarns \\
\hline 05 & Vivid Green & 55 & & 78 & & & & & 2 Times & $=219$ yarns \\
\hline 06 & South Sea & & & 219 & & & & & 1 Time & $=63$ yarns \\
\hline 07 & Bold Orange & & & & & & 63 & & & 1 Time \\
\hline & & & & & & & & & Total 12 times & 2001 yarns \\
\hline
\end{tabular}

Color sequence: As per given serial below the CAD (“P”), left to right, DC:

\section{Warp Chart or Warp Pattern Description:}

Chart Movement: from up to down direction. (Inside the chart only).

$1^{\text {st }}$ Column: This is the serial number of row.

$2^{\text {nd }}$ column: This is the serial of warp pattern as per given below the CAD in "P". According to that serial of CAD, we will arrange the warp pattern.

$3^{\text {rd }}$ column: This is the starting of $1^{\text {st }}$ yarns sequence. The first sequence of color in CAD is Vivid Green, which is in serial number 05 row, in the chart that is 55 yarns. In $3^{\text {rd }}$ column there is no other color.

$4^{\text {th }}$ column: After vivid green, the next color is blue ink in CAD. In $3^{\text {rd }}$ column, it stays above vivid green. Blue ink stays above and vivid green stays below. As the chart movement is from up to down, so blue ink yarns could not be placed in $3^{\text {rd }}$ column. It will stay in $4^{\text {th }}$ column.

$5^{\text {th }}$ column: After blue ink, the next color is white in CAD. In $4^{\text {th }}$ column, white stays above blue ink. White stays above and blue ink stays below. As chart movement is from up to down direction, white yarns could not be placed in $4^{\text {th }}$ column. White yarns will go to $5^{\text {th }}$ column. After white yarns, there is present blue ink yarns. White stays above and blue ink stays below. As chart movement is from up to down direction, and in $5^{\text {th }}$ column, blue ink stays below white yarns, so blue ink will also be placed in $5^{\text {th }}$ column. Then vivid green and south sea will also be placed in $5^{\text {th }}$ column as per system.

$6^{\text {th }}$ column: After south sea, there present Ruby Pop colored yarns in CAD. Ruby Pop Stays above south sea color. Ruby pop stays above and south sea stays below. Chart movement is from up to down direction, so ruby pop will be placed in next column that is $6^{\text {th }}$ column.

$7^{\text {th }}$ Column: After ruby pop there is present blue ink and ruby pop in CAD. Blue ink stays above ruby pop. Blue ink stays above and ruby pop stays below. As the chart movement is from up to down direction, so blue ink could not be placed in $6^{\text {th }}$ column. Blue ink and ruby pop will be placed in the next column, that is column $7^{\text {th }}$. In row two there is blue ink and in row four, there is ruby pop of $7^{\text {th }}$ column.

$8^{\text {th }}$ column: After ruby pop there is aqua pool color in CAD. But in chart, aqua pool stays above ruby pop. Aqua pool stays above and ruby pop stays below. As chart movement is from up to down direction, so aqua pool could not be placed in $7^{\text {th }}$ column. Aqua pool color will be placed in the next column that is column $8^{\text {th }}$. After aqua pool color there is bold orange color in CAD. Here aqua pool stays above and bold orange stays below. Chart movement is from up to down direction. So bold orange will be placed in the same column that is column $8^{\text {th }}$.

$9^{\text {th }}$ column: After bold orange, the next color is aqua pool in CAD. In $8^{\text {th }}$ column, aqua pool stays above bold orange. Aqua pool stays above and bold orange stays below. As the chart movement is from up to down direction, so aqua pool yarns could not be placed in $8^{\text {th }}$ column again after bold orange. It will stay in the next column that is column $9^{\text {th }}$.

$10^{\text {th }}$ column: This expresses the frequency of color yarn. How many times does a color yarn come in a repeat that will calculate in this column. 
$11^{\text {th }}$ column: This column expresses the number of yarns stay in each color and also expresses the total number of yarns required for the whole repeat.

\section{Weft pattern chart}

(Table 6)

Table 6: Weft pattern chart.

\begin{tabular}{|c|c|c|c|c|c|c|c|c|c|c|}
\hline $1^{\text {st }}$ & $2^{\text {nd }}$ & $3^{\text {rd }}$ & $4^{\text {th }}$ & $5^{\text {th }}$ & $6^{\text {th }}$ & $7^{\text {th }}$ & $8^{\text {th }}$ & $9^{\text {th }}$ & $10^{\text {th }}$ & $11^{\text {th }}$ \\
\hline S.N & Color Names & & & & & & & & Frequency & Total Yarns Or Total Cones \\
\hline 01 & White & & 60 & & & & & & 1 time & 60 \\
\hline 02 & Blue Ink & & & 278 & & & 278 & & 2 times & 556 \\
\hline 03 & Aqua Pool & & & & & 351 & & 29 & 2 times & 380 \\
\hline 04 & Ruby Pop & & & & & & & & No times & 00 \\
\hline 05 & Vivid Green & & & & & & & & No times & 00 \\
\hline 06 & South Sea & 46 & 46 & 46 & 113 & & 60 & & 5 times & 311 \\
\hline \multirow[t]{2}{*}{07} & Bold Orange & & & 292 & & & & & 1 time & 292 \\
\hline & & & & & & & & & Total 11 times & 1599 \\
\hline
\end{tabular}

Color sequence: As per given serial below the CAD ("P"), from down to up, DA:

\section{Weft chart or weft pattern description:}

Chart Movement: from up to down direction (inside the chart only).

$1^{\text {st }}$ Column: This is the serial number of row.

$2^{\text {nd }}$ column: This is the serial of weft pattern as per given below the CAD in "P". According to that serial of CAD, we will arrange the weft pattern.

$3^{\text {rd }}$ column: This is the starting of $1^{\text {st }}$ yarns sequence. The first sequence of color in CAD is south sea, which is in serial number 06 row, in the chart that is 46 yarns. In 3rd column there is no other color.

$4^{\text {th }}$ column: After south sea, the next color is white in CAD. In $3^{\text {rd }}$ column, it stays above south sea. white stays above and south sea stays below. As the chart movement is from up to down, so white yarns could not be placed in $3^{\text {rd }}$ column. It will stay in $4^{\text {th }}$ column. After white color, there is south sea color in CAD. South sea stays below and white stays up. As the chart movement is from up to down direction inside the CAD, so south sea will be placed in $4^{\text {th }}$ column after white [9].

$5^{\text {th }}$ column: After south sea, the next color is blue ink in CAD. In $4^{\text {th }}$ column, south sea stays below of blue ink color. Blue ink stays above and south sea stays below. As chart movement is from up to down direction, blue ink yarns could not be placed in $4^{\text {th }}$ column. Blue ink yarns will go to $5^{\text {th }}$ column. After blue ink yarns, there is present south sea yarns. South sea stays at the same column of blue ink. South sea stays under blue ink. As chart movement is from up to down direction, and in $5^{\text {th }}$ column, south sea stays below blue ink yarns, so south sea will also be placed in $5^{\text {th }}$ column. Then bold orange will also be placed in 5 th column as per system.

$6^{\text {th }}$ column: After bold orange, there present south sea colored yarns in CAD. South sea Stays above bold orange color. South sea stays above and bold orange stays below. Chart movement is from up to down direction, so south sea will be placed in next column that is $6^{\text {th }}$ column.

$7^{\text {th }}$ Column: After south sea there is present aqua pool color in CAD. Aqua pool stays above south sea. Aqua pool stays above and south sea stays below. As the chart movement is from up to down direction, so aqua pool yarns could not be placed in $6^{\text {th }}$ column. Aqua pool yarns will be placed in the next column, that is column $7^{\text {th }}$.

$8^{\text {th }}$ column: After aqua pool there is blue ink color in CAD. But in chart, aqua pool stays below blue ink. Blue ink stays above and aqua pool stays below. As chart movement is from up to down direction, so blue ink could not be placed in $7^{\text {th }}$ column. Blue ink color will be placed in the next column that is column 8th. After blue link color there is south sea color in CAD. Here blue ink stays above and south sea stays below. Chart movement is from up to down direction. So south sea color will be placed in the same column that is column $8^{\text {th }}$.

$9^{\text {th }}$ column: After south sea, the next color is aqua pool in CAD. In $8^{\text {th }}$ column, aqua pool stays above south sea color. Aqua pool stays above and south sea stays below. As the chart movement is from up to down direction, so aqua pool yarns could not be placed in $8^{\text {th }}$ column. It will stay in the next column that is column $9^{\text {th }}$.

$10^{\text {th }}$ column: This expresses the frequency of color yarn. How many times does a color yarn come in a repeat that will calculate this column.

$11^{\text {th }}$ column: This column expresses the number of yarns stay in each color and also expresses the total number of yarns required for the whole repeat.

\section{E. $5^{\text {th }}$ step of CAD analysis}

This step is the dwell period of repeat size of the CAD in the fabric. How much time the repeat size will come in the fabric, (both in warp and weft direction) that can be identified after this step completion.

If we divide the total width of fabric with a full warp repeat then 
we will get how much time the repeat will dwell in the fabric (for warp pattern).

Suppose, the CAD repeat size is 20 inches (warp repeat). The finished width of the fabric is 60 inches. So the repeat will be available in fabric for $3(60 / 20=3)$ times in warp yarn or in warp direction. If we divide the total length with a full weft repeat then we will get how much time the repeat will dwell in the fabric (for weft pattern).

Suppose, the CAD repeat size is 20 inches (weft repeat). The finished length of the fabric is 100 meter $(100 \mathrm{mtr} \times 39.37=3937$ " inches). So the repeat will be available in fabric for 196.85 $(3937 / 20=196.85)$ times in weft yarn.

\section{F. 6th step of CAD analysis}

This is the final step of CAD Calculation. This is the step of proofing the CAD that has already been calculated. After completing this step, we will get a confirmation of CAD Calculation [10].

\section{Verification}

\section{Warp way verification}

Here we can certify the calculation, whether it is correct or incorrect.

The total area of CAD in normal A4 size paper is 5.027 inches. And total number of yarns are $=$

$=$ Area" $\mathrm{x}$ Fraction x EPI.

$=5.027^{\prime \prime} \times 3.9785$ (Fraction) $\times 100$

$=1999.99$

$=2000$ yarns. (In a repeat)

\section{There are two step of proofing:}

\section{i. Step 1:}

Total CAD Repeat is equal to 5.027 inches.

Now I will totaling all the measurement by a liner scale of each color in a repeat, that is $=$

= vivid Green + blue ink + white + blue ink + vivid green + south sea + ruby pop + blue ink + ruby pop + aqua pool + bold orange + aqua pool $=$

$=3.5 \mathrm{~mm}$ or 0.1377 inch $+3.35 \mathrm{~cm}$ or 1.3188 inch $+6 \mathrm{~mm}$ 0r 0.2362 inch $+1.27 \mathrm{~cm}$ or $0.5000 \mathrm{inch}+5 \mathrm{~mm}$ or $0.19685 \mathrm{inch}+1.4 \mathrm{~cm}$ or 0.55118 inch $+6 \mathrm{~mm}$ or 0.23622 inch $+4 \mathrm{~mm}$ or 0.15748 inch $+1 \mathrm{~cm}$ or $0.3937 \mathrm{inch}+8 \mathrm{~mm}$ or $0.31496 \mathrm{inch}+4 \mathrm{~mm}$ or $0.15748 \mathrm{inch}$ $+2.1 \mathrm{~cm}$ or 0.82677 inch

$=5.027$ inches.

CAD Repeat size is 5.027 inches and individually, every color measurement altogether is 5.027 inches.

CAD Repeat Size $=$ Individual Color Measurement.
5.027 inches $=5.027$ inches .

So 1 st step is ok.

\section{ii. Step 2:}

If we count and add all the yarn in a repeat from the chart (3rd step), that is =

= vivid Green + blue ink + white + blue ink + vivid green + south sea + ruby pop + blue ink + ruby pop + aqua pool + bold orange + aqua pool=

$=55+525+94+199+78+219+94+63+157+125+63+329$

$=2001$ yarns

Total yarns are in a repeat is 2000 and individual yarn measurement is 2001 .

Theoretical CAD Repeat yarns $=$ or $\approx$ Summation of Practically obtained individual yarn.

$2000 \approx 2001$

So these two values are equal or approximate which certify that the given CAD analysis /Calculation is correct.

(*** For every 100 yarns, \pm 1 yarn more or less is considerable in industries. That means in case of 100 yarns, 99 to 101 yarns are considerable. So for 2000 yarns, \pm 20 yarns more or less is considerable. That means, for 2000 yards, 1980 to 2020 yarns are considerable.)

$2^{\text {nd }}$ step is also ok.

\section{Weft way verification}

Here we can certify the calculation, whether it is correct or incorrect in weft way [11].

In weft way, the total area of CAD in normal A4 size paper is 4.75 " inches. So total number of yarns in weft repeat are $=$

$=$ Area" $\mathrm{x}$ Fraction $\mathrm{x}$ PPI.

$=4.75^{\prime \prime} \times 4.21$ (Fraction) $\times 80$

$=1599.80$

$=1600$ yarns. (In a weft repeat)

\section{There are two step of proofing:}

\section{i. Step 1:}

Total CAD Repeat is equal to 4.75 " inches.

Now I will totaling all the measurement by a liner scale of each color in a repeat, in weft way that is =

$=$ south sea + white + south sea + blue ink + south sea + bold orange + south sea + aqua pool + blue ink + south sea + aqua pool $=$

$=3.5 \mathrm{~mm}$ or $0.1377 \mathrm{inch}+4.5 \mathrm{~mm}$ or $0.177165^{\prime \prime}$ inch $+3.5 \mathrm{~mm}$ or 0.1377 inch $+2.1 \mathrm{~cm}$ or 0.826771 " inch $+3.5 \mathrm{~mm}$ or 0.1377 inch $+2.2 \mathrm{~cm}$ or $0.866141^{\prime \prime}$ inch $+8.5 \mathrm{~mm}$ or $0.3347^{\prime \prime}$ inch $+2.65 \mathrm{~cm}$ or $1.0433^{\prime \prime}$ inch $+2.1 \mathrm{~cm}$ or 0.826771 " inch $+4.5 \mathrm{~mm}$ or $0.177165^{\prime \prime}$ inch 
$+2.2 \mathrm{~mm}$ or $0.0866141^{\prime \prime}$ inch $=$

$=4.75$ inches.

CAD Repeat size is $4.75^{\prime \prime}$ inches and individually, every color measurement altogether is $4.75^{\prime \prime}$ inches.

CAD Repeat Size $=$ Individual Color Measurement.

$4.75^{\prime \prime}$ inches $=4.75^{\prime \prime}$ inches.

So 1 st step is ok.

\section{ii. Step 2:}

If we count and add all the yarn in a repeat from the chart (3rd step), that is $=$

$=$ south sea + white + south sea + blue ink + south sea+ bold orange + south sea + aqua pool + blue ink + south sea + aqua pool $=$

$=46+60+46+278+46+292+113+351+278+60+29=$

$=1599$ yarns.

Total yarns are in a repeat is 1600 and individual yarn measurement is 1599 .

Theoretical CAD Repeat yarns $=$ or $\approx$ Summation of Practically obtained individual yarn.

$1600 \approx 1599$

So this two values are equal or approximate which certify that the given CAD Calculation/ analysis is correct.

(*** For every 100 yarns, \pm 1 yarn more or less is considerable in industries. That means in case of 100 yarns, 99 to 101 yarns are considerable. So for 1600 yarns, \pm 16 yarns more or less is considerable. That means, for 1600 yarns, 1584 to 1616 yarns are considerable.)

$2^{\text {nd }}$ step is also ok.

So we can say that the given CAD calculation/ analysis is correct.

\section{Conclusion}

At last we can say that, there are some significance of this CAD analysis in the field of textiles cloth manufacturing. Warp patterning

Creative Commons Attribution 4.0

International License

For possible submissions click Here and Weft patterning is required in yarn dyed fabric. The color pattern while warping and color patter during weaving for weft patterning in loom is possible to make with the help of this work [12]. This project is a practical based work that can develop skill among textile design learners for yarn dyed fabric development. The warp and weft way patterning was seen in this project and how the textile preparatory process like warping will be designed that was also seen in this project. Total number of cones required in full repeat and in the full fabric was seen in this project. Warp and weft color sequence, color measurement, warp and weft patterning were shown in this project with verification.

\section{References}

1. Greenwood k, Vaughan G (1959) The effect of weft yarn irregularity on pick spacing and weft cover factor. Journal of the Textile Institute Transactions 50(5): t337-t352.

2. Anon (2017) http://textile cad analysis for warp and weft patterning designing drawing drafting.

3. Dormor c (2014) Warp \& weft: woven textiles in fashion, art and interiors, jessica hemmings. Textile 12(2): 255-257.

4. Lomax j (1949) A suggested method of testing woven fabrics for measurement of resistance to slippage of warp threads over the weft, or weft over the warp. Journal of the Textile Institute Transactions 40(8): t525-t526.

5. Karnoub A (2015) The effect of warp and weft variables on fabric?s shrinkage ratio. Journal of Textile Science \& Engineering 05(02)

6. Zhang Z, yu C (2011) Study on drafting force and sliver irregularity on drawing frame. Journal of the Textile Institute 103(2): 1-7.

7. Mcmahon J (1986) Weft tension during double-rapier weft insertion in weaving. Journal of the Textile Institute 77(5): 356-358.

8. Garaventa D (1981) A discontinuous warp and weft textile of early horizon date. Ñawpa Pacha 19(1): 167-176.

9. Tevis J (2015) Warp and weft. Places journal.

10. Ghosh GC, Bhaduri SN (1962) Dependence of hook removal at drawing on some drafting parameters. Textile Research Journal 32(10): 864-866.

11. Hartley H (1926) 25-fabric analysis-the contraction of warp and weft. Journal of the Textile Institute Transactions 17(5): t254-t258.

12. Kendall F (1949) [the institute is not responsible for the opinions of correspondents.] A suggested method of testing woven fabrics for the measurement of resistance to slippage of warp threads over the weft, or weft over warp. Journal of the Textile Institute Transactions 40(4): t247-t252.

Your subsequent submission with Crimson Publishers will attain the below benefits

- High-level peer review and editorial services

- Freely accessible online immediately upon publication

- Authors retain the copyright to their work

- Licensing it under a Creative Commons license

- Visibility through different online platforms

- Global attainment for your research

- Article availability in different formats (Pdf, E-pub, Full Text)

- Endless customer service

- Reasonable Membership services

- Reprints availability upon request

- One step article tracking system 